\title{
IDENTIFICATION AND EXPRESSION ANALYSIS OF TWO DEVELOPMENTALLY REGULATED MYOSIN HEAVY CHAIN GENE TRANSCRIPTS IN CARP (CYPRINUS CARPIO)
}

\author{
STEVEN ENNION ${ }^{1}$, DAVID WILKES $^{1}$, LAURENT GAUVRY $^{1, *}$, HÉLENE ALAMI-DURANTE $^{2}$ \\ AND GEOFFREY GOLDSPINK ${ }^{1, *}$ \\ ${ }^{1}$ Department of Anatomy and Developmental Biology, Royal Free and University College Medical School, \\ Rowland Hill Street, London NW3 2PF, UK and ${ }^{2}$ Unité Mixte INRA-IFREMER de Nutrition des Poissons, \\ Station d'Hydrobiologie INRA, BP.3, 64310 Saint Pée sur Nivelle, France \\ *Present address: Département Génie Biologie, Institut Universitaire de Technologie de Laval, 52 rue des docteurs Calmette et Guérin BP40, \\ 53020 Laval, France \\ \$Author for correspondence (e-mail: goldspink@rfhsm.ac.uk)
}

Accepted 15 February; published on WWW 6 April 1999

\begin{abstract}
Summary
Whilst developmentally regulated genes for the myosin heavy chain $(\mathrm{MyoHC})$ have been characterised in mammalian, avian and amphibian species, no developmental MyoHC gene has previously been characterised in a species of fish. In this study, we identify two developmentally regulated $\mathrm{MyoHC}$ gene transcripts (named Eggs22 and Eggs24) in carp (Cyprinus carpio) and characterise their expression patterns during embryonic and larval development. The transcripts showed an identical temporal pattern of expression commencing $22 \mathrm{~h}$ post-fertilisation $\left(18^{\circ} \mathrm{C}\right.$ incubation temperature), coincident with the switch from exclusive expression of genes for $\beta$-actin to expression of genes for both $\beta$ - and $\alpha$ actin, and continuing for 2 weeks post-hatching. No expression of these myosin transcripts was detected in juvenile or adult carp. Wholemount in situ hybridisation showed that both transcripts are expressed initially in the rostral region of the developing trunk and progress

caudally. Both are expressed in the developing pectoral fin and protractor hyoideus muscles. However, the muscles of the lower jaw express only the Eggs22 transcript. No expression of either transcript was detected in cardiac or smooth muscle. A distinct chevron pattern of expression was observed in the myotomal muscle. This was shown to be caused by localisation of the mRNAs to the myoseptal regions of the fibres, the sites of new sarcomere addition during muscle growth, suggesting transport of $\mathrm{MyoHC}$ mRNA transcripts. The $3^{\prime}$ untranslated region of the Eggs24 transcript contains a 10 base pair motif (AAAATGTGAA) which is shown to be also present in the $3^{\prime}$ untranslated regions of $\mathrm{MyoHC}$ genes from a wide range of species. Possible reasons for the need for developmental isoforms of myosin heavy chain isoforms are discussed.

Key words: myosin heavy chain, muscle, development, in situ hybridisation, carp, Cyprinus carpio, muscle.
\end{abstract}

\section{Introduction}

The precursors of muscle fibres are mononucleated embryonic mesodermal cells which do not themselves synthesize any of the muscle-specific myofibrillar proteins. During muscle formation, these cells proliferate and differentiate into mononucleated myoblasts, which fuse to form multinucleated myotubes. In mammals, a biphasic process of muscle fibre formation is observed. The first myotubes to form are known as primary myotubes, and these provide a framework along which remaining myotubes orientate themselves longitudinally and subsequently fuse to form the secondary myotubes. This process initially leads to a 'rosette' arrangement of muscle fibres, with the larger primary myotubes surrounded by smaller secondary myotubes. The difference in size between primary and secondary myotubes gradually diminishes until the two populations are indistinguishable in the adult. In fish, this biphasic development of primary and secondary myotubes is not observed. However, the origins of different muscle fibres are both spatially and temporally segregated. In zebrafish, adaxial cells of the segmental plate migrate radially from a position adjacent to the notochord to the lateral surface of the myotome, where they differentiate into slow muscle fibres. In contrast, the fast muscle fibres arise from lateral presomatic cells that do not contact the notochord (Devoto et al., 1996). Subsequent to the formation of the inner white and superficial red zones of muscle in the embryo and yolk-sac larvae, a second stage of muscle development occurs in the freeswimming larvae when the adult red and pink fibre types form and a new phase of fibre hyperplasia begins in the white muscle zone. The newly formed small muscle fibres in these 
later stages of development have been shown to be immunohistochemically different from more mature fibres (Rowlerson et al., 1985; Akster, 1983).

The molecular motors driving muscle contraction are the myosin heavy chains (MyoHC), and a complex pattern of MyoHC isoforms is expressed during muscle fibre development. In rat and human, the primary muscle fibres initially express the embryonic (Strehler et al., 1986; KarschMizrachi et al., 1989; Eller et al., 1989a; Molina et al., 1987), neonatal (termed perinatal in human) (Weydert et al., 1987; Feghali and Leinwand, 1989; Periasamy et al., 1984) and the slow $\beta$ cardiac (Narusawa et al., 1987; Barbet et al., 1991) $\mathrm{MyoHC}$ isoforms, but none of the fast MyoHC isoforms. The secondary fibre population of myotubes express embryonic, neonatal and fast MyoHC isoforms in a heterogeneous manner, but never express (at least in humans) the slowtwitch MyoHC isoform (Barbet et al., 1991). Later in embryonic development (at approximately 35 weeks of gestation in the human), embryonic isoform expression decreases, and shortly after birth expression of the neonatal isoform also disappears. Concomitantly with the elimination of the embryonic and neonatal isoforms, the adult slow and fast $\mathrm{MyoHC}$ isoforms begin to be expressed predominantly as the muscle takes on its adult phenotype. Also at this stage, certain fibres cease to express the slow $\beta$ cardiac isoform and begin to express the adult fast isoforms (Barbet et al., 1991). The myosin heavy chain isoform transitions occurring during embryonic development in the rabbit have been quantified at the mRNA level by RNAase protection assay, and these changes are closely mirrored by changes in the corresponding proteins, suggesting that the control of isoform transitions occurs at the transcription level (McKoy et al., 1998). Immunological studies (Hughes et al., 1993) suggest that at least three different slow MyoHC isoforms are expressed during development in rat; however, there is no evidence for this at the gene level. A second embryonic MyoHC isoform has also been described in chicken skeletal muscle (Hofmann et al., 1988). Xenopus laevis has been shown to express at least two 'embryonic' isoforms, named E3 and E19 (Radice and Malacinski, 1989), with the E3 isoform being predominant in the larval type II fibres, whilst the E19 isoform is predominant in the type I fibres. However, a significant proportion of type I and type II fibres co-express both isoforms (Radice, 1995).

The family of sarcomeric MyoHC isoforms expressed in all vertebrate species studied to date has been shown to be large and complex, with the individual isoforms being very similar in size (about $220 \mathrm{kDa}$ ) and sharing many common epitopes. This has often hampered the distinction of separate isoforms at the protein level by electrophoretic or immunological means. To date, the most definitive way of characterising different $\mathrm{MyoHC}$ isoforms in a species has been to isolate the gene sequence for the separate isoforms because each individual isoform in vertebrate species is encoded by a separate gene. Whilst the genes coding for the mammalian and some avian MyoHC isoforms are well characterised, relatively few piscine $\mathrm{MyoHC}$ genes have been studied, of which none correspond to isoforms expressed exclusively during embryonic development. The aim of the present study was to characterise those $\mathrm{MyoHC}$ genes that are expressed in developing carp (Cyprinus carpio) embryos. The high levels of sequence homology which have been shown to exist between all MyoHC isoforms studied to date dictates that nucleotide probes to be used for the characterisation of the expression patterns of different isoforms within the same species have to be chosen with care. Probes covering the coding region of the gene have been shown to cross-hybridise to a number of $\mathrm{MyoHC}$ isoforms within the same species (Stedman et al., 1990; Eller et al., 1989b), making them of limited use in determining the expression patterns of individual isoforms. Therefore, the strategy adopted in the present study was to isolate the $3^{\prime}$ ends of $\mathrm{MyoHC}$ isogenes and use the $3^{\prime}$ untranslated region ( $3^{\prime}$ UTR) as isogene-specific probes to map expression patterns using northern and in situ hybridisations.

\section{Materials and methods \\ Animals}

Carp eggs were fertilized at the INRA Station d'Hydrobiologie, Saint Pée sur Nivelle, France. Embryos were incubated and larvae reared at $18{ }^{\circ} \mathrm{C}$ according to the protocol described by Alami-Durante et al. (1997).

\section{Oligonucleotides}

The primers RoRidT17 (5'ATCGATGGTCGACGCATGCGGATCCAAAGCTTGAATTCGAGCTCTTTTTTTTTTTTTTTTT3') and Ro (5'ATCGATGGTCGACGCATGCGGATCC $3^{\prime}$ ) were synthesized according to the sequence designed by Harvey and Darlison (1991). The Ro primer corresponds to the first 25 nucleotides of the RoRidT17 primer that was used to prime cDNA synthesis. The oligonucleotide primer FG2EXN40 (5'AGGAAGGTCGAGCATGAACTGGAGG3') was synthesised to correspond to part of the exon 40 sequence of the carp FG2 MyoHC gene (Ennion et al., 1995a). The expected size of the amplified polymerase chain reaction (PCR) product from the FG2 $\mathrm{MyoHC}$ gene is approximately 250 bp long when the FG2EXN40 and Ro primers are used. The oligonucleotides EGGS2224F (5'GACAAAGCTTAGTCTCA3'), EGGS22R (5'TAGGAATTCAGATTTATTTC3') and EGGS24R (5'GATGAATTCAATGCTTTAT3') were designed on the basis of the sequence of myosin heavy chain containing PCR clones from FG2EXN40/Ro amplifications. EGGS2224F had a HindIII restriction site incorporated in the sequence, whereas EGGS22R and EGGS24R had EcoRI sites incorporated to facilitate subcloning into $\mathrm{pBS}^{(+)}$vector (Stratagene).

\section{cDNA synthesis}

Total RNA $(20 \mu \mathrm{g})$ extracted from pre-hatched carp embryos by the method described by Chomczynski and Sacchi (1987) was resuspended in diethylpyrocarbonate (DEPC)-treated 


\section{Developmental myosin heavy chain isoforms in carp 1083}

water, heated to $65^{\circ} \mathrm{C}$ for $5 \mathrm{~min}$, and rapidly cooled on ice. To this was then added 40 units of RNAase inhibitor (Promega), $5 \mu \mathrm{l}$ of $5 \times$ reverse transcriptase buffer $\left(500 \mathrm{mmol}^{-1}\right.$ Tris- $\mathrm{HCl}$, $600 \mathrm{mmol}^{-1} \mathrm{KCl}, 100 \mathrm{mmoll}^{-1} \mathrm{MgCl}_{2}, \mathrm{pH} 8.15$ at $\left.42^{\circ} \mathrm{C}\right), 5 \mu \mathrm{l}$ of dNTP stock ( $5 \mathrm{mmol}^{-1}$ for each nucleotide), $500 \mathrm{ng}$ of the oligonucleotide primer RoRidT17, $0.5 \mu \mathrm{l}$ of $1 \mathrm{moll}^{-1}$ dithiothreitol (DTT), $0.5 \mu \mathrm{l}$ (7.5 units) of Rous-associated-virus reverse transcriptase (Amersham) and DEPC-treated water to a final volume of $25 \mu \mathrm{l}$. Control reactions, identical to those described above but with no reverse transcriptase enzyme added, were also performed to rule out possible contamination of genomic DNA. Reaction mixtures were incubated at $42{ }^{\circ} \mathrm{C}$ for $2 \mathrm{~h}$ and stored at $-20^{\circ} \mathrm{C}$.

\section{Polymerase chain reaction}

PCR amplifications of first-strand cDNA were performed using a recombinant Taq DNA polymerase (Boehringer Mannheim). Each reaction contained $1 \mu \mathrm{l}$ of unpurified firststrand cDNA, $5 \mu$ l of $10 \times$ Taq polymerase buffer, 25 pmol of Ro primer, 25 pmol of FG2EXN40 primer, $2 \mu \mathrm{l}$ of dNTP stock $\left(5 \mathrm{mmoll}^{-1}\right.$ of each nucleotide in stock) and 5 units of Taq polymerase (added after a 'hot start') in a reaction volume of $50 \mu \mathrm{l}$. Control reactions, with no template added, were also performed to verify that contaminating DNA was absent. Reaction conditions were $94^{\circ} \mathrm{C}$ for $1 \mathrm{~min}, 55^{\circ} \mathrm{C}$ for $1 \mathrm{~min}$ and $72^{\circ} \mathrm{C}$ for $2 \mathrm{~min}$ for 25 cycles. After the last amplification cycle, samples were incubated at $72^{\circ} \mathrm{C}$ for $5 \mathrm{~min}$ to extend incomplete products. PCR products were then analysed by gel electrophoresis on $2 \%$ agarose gels made in TAE buffer (4 mmoll ${ }^{-1}$ Tris-Hcl, $4 \mathrm{mmoll}^{-1}$ sodium acetate, $2 \mathrm{mmol}^{-1}$ EDTA). PCR products were isolated from agarose gels using a 'Prepagene' kit (Bio-Rad) and subcloned into Bluescript $\mathrm{pBS}^{(+)}$phagemid (Stratagene) using the T-A cloning method described by Marchuk et al. (1991). DNA sequencing was performed by the chain termination method (Sanger et al., 1977).

\section{Probe synthesis}

The plasmids EGGS22UTR and EGGS24UTR were constructed to facilitate production of isoform-specific probes that contained $3^{\prime}$ untranslated region sequence but no poly(A) tail. These plasmids contained PCR products amplified with EGGS2224F/EGGS22R (for EGGS22UTR) and EGGS2224F/EGGS24R (for EGGS24UTR) primers using EGGS22 and EGGS24 plasmid DNA as template and cloned into $\mathrm{pBS}^{(+)}$(Stratagene) vector at the EcoRI/HindIII restriction sites. For northern hybridisation probes, the 'UTR' plasmids were linearised with HindIII, and EGGS22R or EGGS24R was used for specific primer extension with $\left[\alpha-{ }^{32} \mathrm{P}\right] \mathrm{dATP}$ (3000 $\mathrm{Ci} \mathrm{mmol}^{-1}$, Amersham International) as label. The carp actin probe FGA101 (Gerlach et al., 1990), which hybridises to both $\alpha$ - and $\beta$-actin, was labelled by random priming (Feinberg and Vogelstein, 1984). cRNA probes for in situ hybridisation were produced from linearised plasmid by $\mathrm{T} 3$ or T7 RNA polymerase (EcoRI linearised/T3 polymerase for the sense probe, HindIII/T7 polymerase for the antisense probe) using digoxigenin-11-UTP as label, according to the manufacturer's instructions (Boehringer Mannheim).

\section{Northern hybridisation}

Total RNA was extracted by the method described by Chomczynski and Sacchi (1987). Electrophoresis of RNA $(30 \mu \mathrm{g})$ was performed in $1.5 \%$ agarose gels prepared in MOPS buffer $\left(0.02 \mathrm{~mol} \mathrm{l}^{-1}\right.$ MOPS, $5 \mathrm{mmol}^{-1}$ sodium acetate, $1 \mathrm{mmoll}^{-1}$ EDTA, pH 7.0) with $0.66 \mathrm{moll}^{-1}$ formaldehyde. RNA was transferred to 'Zeta Probe' nylon membrane (Bio$\mathrm{Rad}$ ) in $10 \times$ standard saline citrate (SSC; $1 \times \mathrm{SSC}$ is $0.15 \mathrm{~mol} \mathrm{l}^{-1}$ $\mathrm{NaCl}, 0.015 \mathrm{moll}^{-1}$ sodium citrate) and fixed by baking at $80^{\circ} \mathrm{C}$ for $2 \mathrm{~h}$. Hybridisation and subsequent washes were carried out at $15^{\circ} \mathrm{C}$ below the calculated melting temperature of the probe duplex $\left(64^{\circ} \mathrm{C}\right)$ according to the method of Church and Gilbert (1984) and at a probe concentration of $10^{6}$ counts $\mathrm{ml}^{-1}$. Hybridised probe was detected by exposure of the washed membrane to X-ray film (Du-Pont) at $-70^{\circ} \mathrm{C}$ using an intensifying screen.

\section{In situ hybridisation}

Carp embryos were anaesthetized in $75 \mathrm{mgl}^{-1}$ MS222 (Thomson and Joseph Ltd) followed by fixation in $4 \%$ paraformaldehyde at $4{ }^{\circ} \mathrm{C}$ overnight. Embryos were then dehydrated in methanol $(30 \%, 50 \%, 80 \%, 95 \%, 100 \%$ and $100 \%$ for $10 \mathrm{~min}$ each) and stored at $-20{ }^{\circ} \mathrm{C}$ until required. Embryos for hybridisation were dechorinated using fine forceps under $100 \%$ methanol and washed sequentially (5 min each) in the following buffers: methanol/PBST 1:1, methanol/PBST 3:7, PBST, PBST (PBST is phosphatebuffered saline with $0.1 \%$ Tween-20). Embryos were then refixed for $20 \mathrm{~min}$ in $4 \%$ paraformaldehyde followed by two 5 min washes in PBST. Permeabilisation of the embryos was achieved by digestion with proteinase $\mathrm{K}$ (Boehringer Mannheim, $50 \mu \mathrm{g} \mathrm{ml}^{-1}$ ) in PBST for $10 \mathrm{~min}$ at room temperature followed by a $5 \mathrm{~min}$ wash in PBST. Embryos were refixed for $20 \mathrm{~min}$ at room temperature in $4 \%$ paraformaldehyde $/ 0.2 \%$ glutaraldehyde and washed twice in PBST (5 min each). After a 10 min incubation in $0.1 \mathrm{moll}^{-1}$ triethanolamine ( $\mathrm{pH} 8.0$ ) with $2.5 \mu \mathrm{ml}^{-1}$ acetic anhydride followed by two $10 \mathrm{~min}$ washes in PBST, embryos were incubated for $1 \mathrm{~h}$ in hybridisation buffer $(50 \%$ formamide $5 \times \mathrm{SSC}, 0.1 \%$ Tween-20, $50 \mu \mathrm{g} \mathrm{ml}^{-1}$ heparin, $10 \mu \mathrm{g} \mathrm{ml}^{-1}$ yeast tRNA) at $65^{\circ} \mathrm{C}$ with one change of buffer. Embryos were hybridised overnight at $65^{\circ} \mathrm{C}$ in preheated hybridisation buffer containing sense or antisense cRNA probe at a concentration of $1 \mathrm{ng} \mu \mathrm{l}^{-1}$. Post-hybridisation washes consisted of the following: $50 \%$ formamide $/ 2 \times \mathrm{SSC}$ for $30 \mathrm{~s}$ at room temperature (to remove the majority of unbound probe), $50 \%$ formamide $/ 2 \times \mathrm{SSC} 1 \mathrm{~h}$ at $65^{\circ} \mathrm{C}$, three $10 \mathrm{~min}$ washes in $2 \times \mathrm{SSC}$ at $37^{\circ} \mathrm{C}$ and one $5 \mathrm{~min}$ wash in PBST at room temperature. Unbound probe was further removed by digestion with a mixture of RNAase A $\left(20 \mu \mathrm{g} \mathrm{ml}^{-1}\right)$ and RNAase T1 (100 units ml-1) in PBST for $1 \mathrm{~h}$ at $37^{\circ} \mathrm{C}$ with shaking. Embryos were further washed in $2 \times \mathrm{SSC}$ for $10 \mathrm{~min}$ at $37^{\circ} \mathrm{C}, 2 \times \mathrm{SSC}$ for $15 \mathrm{~min}$ at $55^{\circ} \mathrm{C}, 0.2 \times \mathrm{SSC}$ for $15 \mathrm{~min}$ at 


\section{S. ENNION AND OTHERS}

$55^{\circ} \mathrm{C}$ (twice) and PBST for $5 \mathrm{~min}$ at room temperature. For detection of hybridised probe, alkaline-phosphataseconjugated anti-digoxigenin antibody (Boehringer Mannheim) was used as follows: incubation in solution B (PBS with $0.2 \%$ Tween-20, $0.2 \%$ Triton X-100 and $2 \%$ sheep serum) for $1 \mathrm{~h}$ at room temperature followed by incubation with preabsorbed antibody in buffer B at a final antibody dilution of 1:4000 overnight at $4{ }^{\circ} \mathrm{C}$ (antibodies were preabsorbed by incubating for $1 \mathrm{~h}$ at a dilution of 1:400 in buffer B with embryos that had been treated as described above but with no probe in the hybridisation buffer). Unbound antibody was removed with two $10 \mathrm{~s}$ washes in solution B, three 30 min washes in solution $\mathrm{B}$, one $30 \mathrm{~min}$ wash in solution B plus $1 \mathrm{mmoll}^{-1}$ levamisol and three $10 \mathrm{~min}$ washes in detection buffer $\left(100 \mathrm{mmoll}^{-1}\right.$ Tris- $\mathrm{HCl}, \mathrm{pH} 9.0,50 \mathrm{mmoll}^{-1}$ $\mathrm{MgCl}_{2}, 100 \mathrm{mmol}^{-1} \mathrm{NaCl}, 0.1 \%$ Tween-20, $1 \mathrm{mmoll}^{-1}$ levamisol), all at room temperature. Colour precipitation was performed with NBT/X-phosphate (Boehringer Mannheim) overnight at $4{ }^{\circ} \mathrm{C}$ in darkness. The reaction was stopped by incubation in PBS containing $1 \mathrm{mmoll}^{-1}$ EDTA, and the embryos were visualised and photographed on an Olympus SZH10 microscope using darkfield illumination. Hybridised wholemount embryos were subsequently processed for wax embedding using standard histochemical techniques, and $10 \mu \mathrm{m}$ sections were cut, stained with eosin and viewed with a Nikon eclipse E800 microscope using brightfield illumination.

\section{Results}

Two distinct MyoHC clones were obtained by PCR

PCR amplification using the FG2EXN40/Ro primers yielded a faint smear of PCR product with a prominent band at approximately $250 \mathrm{bp}$ (Fig. 1). No bands were observed in the control reaction lacking template or in the control reaction lacking reverse transcriptase. The $250 \mathrm{bp}$ band was cloned, and multiple colonies were sequenced. Two different types of clone were isolated from this band (multiple clones for each type), and these were named EGGS22 and EGGS24 (Fig. 2). The clones encoded the carboxy-terminal region and the $3^{\prime} \mathrm{UTR}$ of two MyoHC transcripts which were named Eggs 22 and Eggs 24 respectively. Both sequence types showed a high degree of sequence homology at the deduced amino acid level to equivalent regions of mammalian myosin heavy chain sequences (Fig. 3). The regions of the two transcripts that were used as probe (EGGS22UTR and EGGS24UTR plasmids, underlined sequence in Fig. 2) had $51.7 \%$ sequence similarity determined using the CLUSTAL programme of Higgins and Sharp (1988) and did not hybridise to one another on Southern blots (data not shown).

\section{Expression of the Eggs22 and Eggs24 MyoHC transcripts is developmentally regulated}

To determine the temporal expression pattern of the two $\mathrm{MyoHC}$ transcripts, northern blots of RNA from successive developmental stages and from adult tissue were probed.

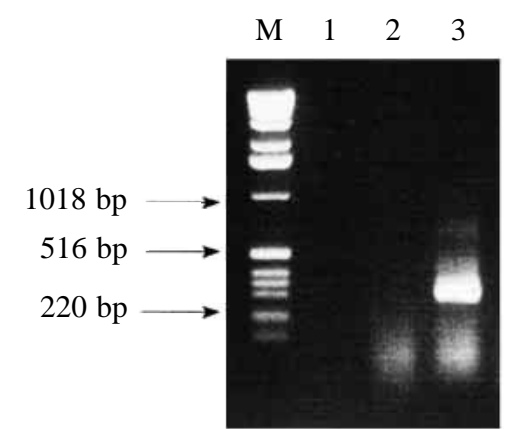

Fig. 1. Electrophoresis of polymerase chain reactions. Lane M, DNA size marker (1 kb ladder; Gibco BRL). Lane 1, control in the absence of template. Lane 2, carp fry cDNA control in the absence of reverse transcriptase. Lane 3, Carp fry cDNA. bp, base pair.

Both the EGGS24UTR and EGGS22UTR probes bound specifically to an RNA transcript of 6 kilobases $(\mathrm{kb})$ in size (Fig. 4). The temporal expression patterns of the two myosin heavy chain transcripts Eggs22 and Eggs 24 was identical at the northern hybridisation level. Both transcripts commenced expression at $22 \mathrm{~h}$ post-fertilisation. This was after somite formation and just before the first movements of the embryo were observed. Expression of the transcripts continued for over 2 weeks after hatching. No expression of the transcripts was detected at 21 or 28 days after hatching (Fig. 4), or in white or red muscle RNA of 12-month-old juvenile carp or adult carp (data not shown). The carp actin probe FGA101 bound to two RNA transcripts corresponding to $\alpha$ - and $\beta$-actin. Expression of the gene for $\beta$-actin was detected in all samples. Expression of the gene for $\alpha$-actin, however, commenced at the same time as that for the Eggs22 and Eggs 24 myosin heavy chain transcripts (after $22 \mathrm{~h}$ post

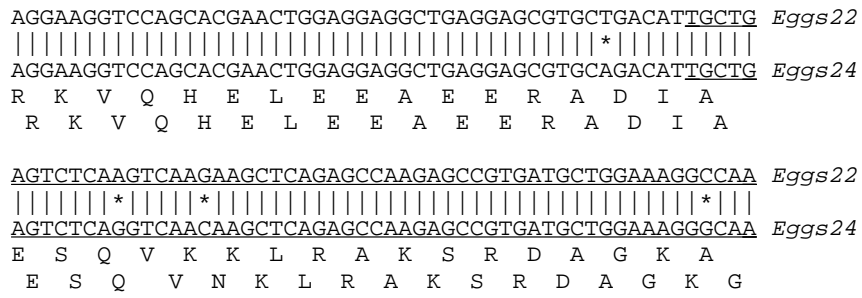

Fig. 2. Nucleotide sequence of EGGS22 and EGGS24 and deduced amino acid sequence of Eggs22 and Eggs24. The underlined sequence indicates the region used as probe for expression analysis. EMBL database accession numbers: EGGS22, AJ009735; EGGS24, AJ009734. 
RKVOHELEEAEERADIAESOVKKLRAKSRDAGKAK----EE RKVQHELEEAEERADIAESQVNKLRAKSRDAGKGKEA--AE RKVOHELEEAOERAD IAESOVNKLRAKSRDAGKSKD---EE RKVQHELDEAEERAD IAESQVNKLRAKSRD I GTKGL--NEE RKVQHELDEAEERADIAESQVNKLRAKSRDIGTKGL--NEE RKVQHELDEAEERAD IAESOVNKLRVKSRDIGAKGL--NEE RKVQHELDEAEERADIAESQVNKLRAKSRDIGTKSL--NEE RKVQHELDEAEERADIAESQVNKLRAKSRDIGAKKM--DEE RKVQHELDEAEERADIAESQVNKLRAKSRDIGAKQKMHDEE RRIQHELEEAEERAD IAESQVNKLRVKSREVHTKI IS--EE RKLQHELEEAEERADIAESQVNKLRVKSREVHTKVIS--EE

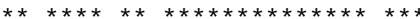

Fig. 3. Amino acid comparison of the carboxy-terminal regions of myosin heavy chain isoforms. Amino acid sequences are given in the one-letter IUPAC code. Sequences and associated references are as follows: (1) carp FG2 (Ennion et al., 1995a); (2) human $\beta$ cardiac (Jaenicke et al., 1990); (3) baboon $\beta$ cardiac (Hixson and Britton, 1988); (4) rat $\beta$ cardiac (Kraft et al., 1989); (5) rabbit $\beta$ cardiac (Kavinsky et al., 1984); (6) human $\alpha$ cardiac (Matsuoka et al., 1991); (7) rat $\alpha$ cardiac (McNally et al., 1989); (8) human fast 2X (Saez and Leinwand, 1986); (9) human fast 2A (Ennion et al., 1995b). An asterisk indicates amino acid residues conserved in all the sequences.

fertilisation) and continued after the Eggs22 and Eggs24 transcripts had ceased to be expressed.

\section{In situ hybridisation}

Wholemount in situ hybridisation with digoxigeninlabelled 3'UTR probes allowed the spatial analysis of the two myosin heavy chain isoforms to be investigated. Staining was completely absent using the sense-labelled cRNA probes for both transcripts at all developmental stages (Fig. 5C and embryos not shown). Using the antisense-labelled probes, expression of both the Eggs22 and Eggs24 MyoHC transcripts was detected in the developing myotomal muscle from approximately $25 \mathrm{~h}$ post-fertilisation. Expression of both isoforms commenced in the rostral region of the trunk and progressed caudally with development (Fig. 5A,B). Staining for the mRNA for both transcripts was stronger at the myoseptal regions, causing a distinct chevron pattern of staining through the trunk musculature (Fig. 5A,B,D). This stronger localisation of message to the myoseptal ends of the developing muscle fibres was also apparent in longitudinal wax-embedded sections (Fig. 5H, arrowheads). The in situ hybridisation protocol used produced complete penetration of the probe as demonstrated by transverse sections through the trunk showing staining throughout the whole of the muscle blocks (Fig. 5G). The hybridisation pattern observed from transverse sections was identical for both transcripts, with strong expression in the myotomal blocks of developing white muscle fibres but no expression in the peripheral layer of developing red muscle fibres (Fig. 5G).

Expression of both $\mathrm{MyoHC}$ transcripts could also be detected in the developing pectoral fin and protractor hyoideus muscles (Fig. 5E,F). Expression in the developing pectoral fin could be localised to two thin strips of muscle. Expression of the Eggs 22 transcript could also be detected in the muscles of the developing lower jaw, producing a distinctive triangular
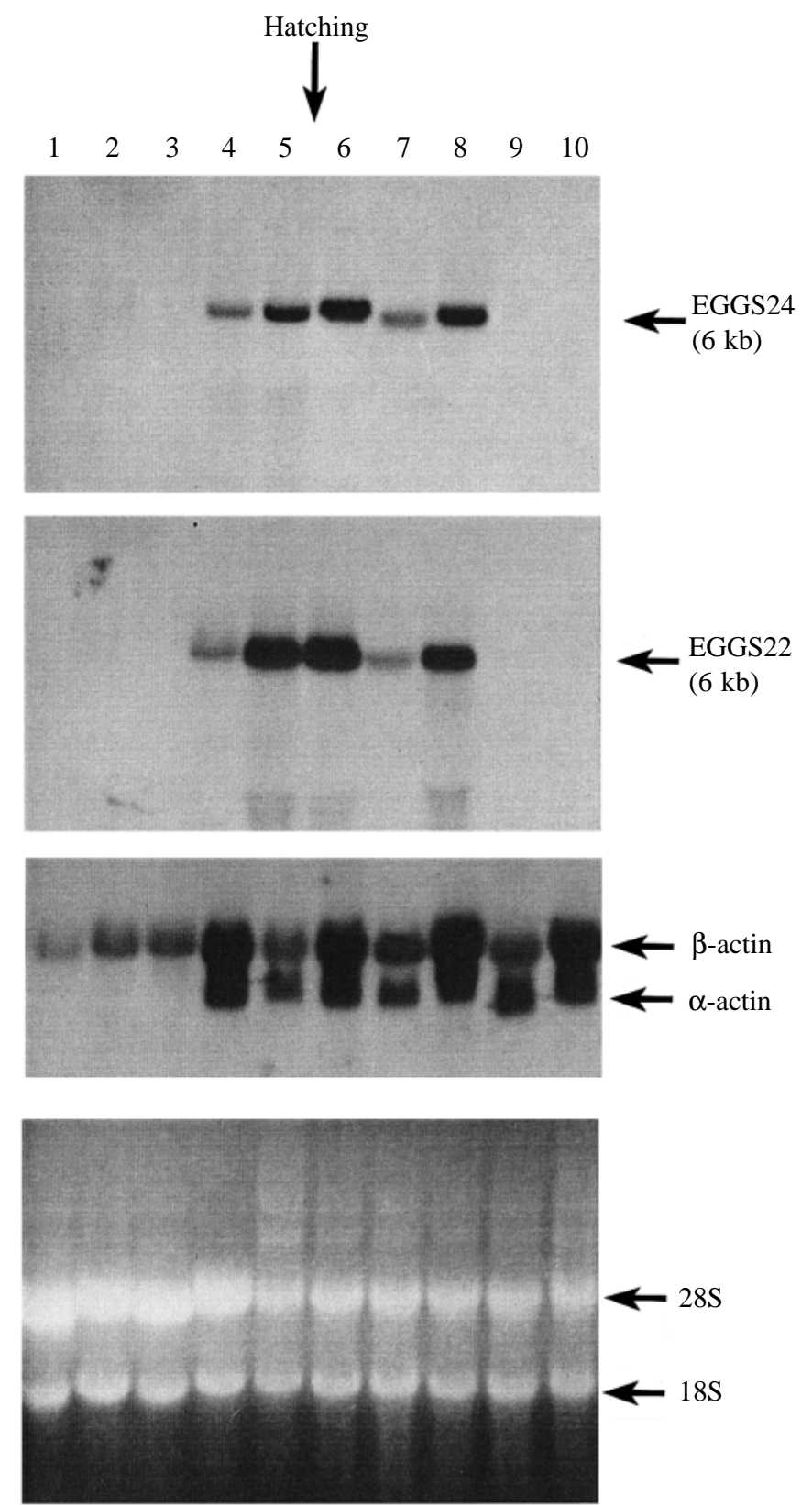

Fig. 4. Northern hybridisation. RNA extracted from carp embryos at different stages of development was probed sequentially with the probes EGGS24UTR (top panel), EGGS22UTR (second panel) and FGA101 (third panel). X-ray film exposure times are $24 \mathrm{~h}$ for each hybridisation. After each hybridisation, the membrane was stripped of probe and re-exposed to film for $48 \mathrm{~h}$ to ensure complete removal. The bottom panel shows the original RNA gel stained with ethidium bromide. Lanes are as follows: (1) $6 \mathrm{~h}$, (2) $16 \mathrm{~h}$, (3) $22 \mathrm{~h}$, (4) $31 \mathrm{~h}$, (5) $36 \mathrm{~h}$ (hatching), (6) 3 days, (7) 7 days, (8) 14 days, (9) 21 days, (10) 28 days. Times are in hours after fertilization and days after hatching. Incubation temperature for embryos and rearing temperature for larvae was $18^{\circ} \mathrm{C}$.

shape (Fig. 5F, arrowhead). The muscles of the lower jaw did not, however, express the Eggs 24 transcript (Fig. 5E). No expression of either transcript was detected in cardiac or smooth muscle. 


\section{Discussion}

Two distinct MyoHC cDNA clones, named EGGS22 and EGGS24, were isolated by random amplification of cDNA ends (RACE)-PCR in this study. The high degree of sequence divergence in the 3'UTRs between these two clones $(42 \%$ similarity) suggests that they correspond to two distinct $M y o H C$ genes rather than to alleles of the same gene or to an evolutionarily recent duplication of the same gene. Duplicated
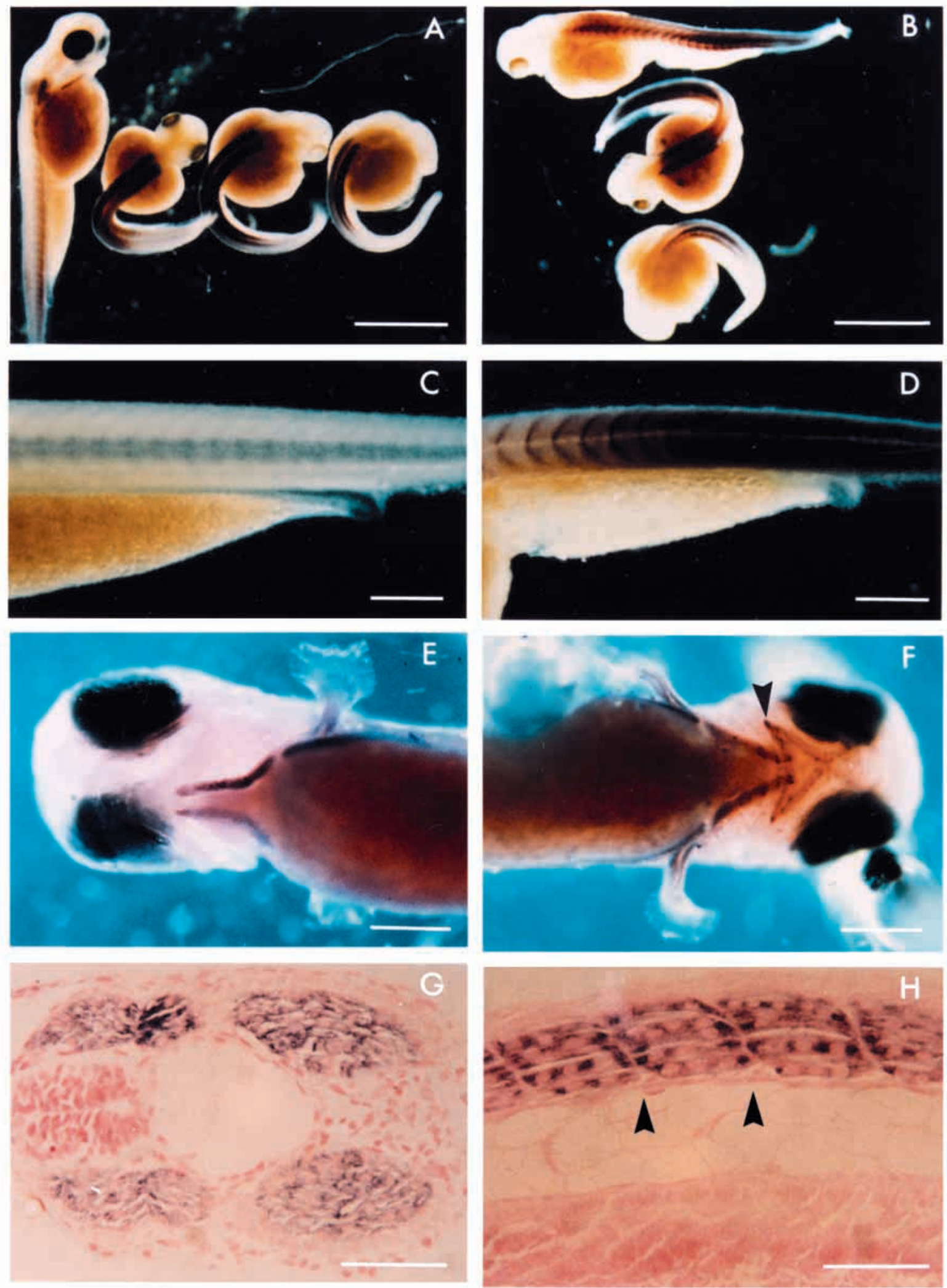
MyoHC genes have been described for Xenopus laevis (Radice and Malacinski, 1989) and trout (Gauvry and Fauconneau, 1996). The process of alternative exon splicing from the same gene cannot be ruled out for the Eggs22 and Eggs24 transcripts. However, this seems unlikely since no evidence for the alternative splicing of exons has been found in any of the numerous vertebrate myosin II heavy chain genes described to date. Mammalian species also express two distinct developmental MyoHC isoforms (the embryonic and neonatal isoforms), and two developmentally regulated MyoHC isoforms (E3 and E19) have been described for Xenopus laevis (Radice, 1995). It is tempting to draw analogies between isoforms across these species. However, the expression patterns of the two carp isoforms are more similar, both temporally and spatially, than those of the mammalian embryonic and neonatal isoforms and the two Xenopus laevis isoforms described to date. Furthermore, at approximately 28 isoforms (Gerlach et al., 1990), the family of MyoHC isoforms in carp is approximately twice the estimated sizes of the mammalian and Xenopus laevis MyoHC isoform families. Therefore, a direct analogy between MyoHC isoforms across species seems inappropriate.

The similarity between the expression pattern of the two carp MyoHC transcripts at both the northern and in situ hybridisation levels raises the question of whether the two probes used in this study cross-hybridise to one another. At the stringencies used in these experiments, the sequence similarity between the probes $(51.7 \%)$ is unlikely to result in any crosshybridisation. Furthermore, the two probes did not crosshybridise on Southern blots (data not shown), and the different hybridisation pattern observed in the muscles of the lower jaw (Fig. 5E,F) confirms that no cross-hybridisation occurred.

The appearance of transcripts for both the Eggs22 and

Fig. 5. In situ hybridisation. Carp embryos were hybridised with digoxigenin-labelled cRNA probes corresponding to the $3^{\prime}$ untranslated regions of the Eggs22 and Eggs24 MyoHC transcripts. (A) Carp embryos (left to right), $12 \mathrm{~h}$ post-hatching, $30 \mathrm{~h}$ postfertilisation, $30 \mathrm{~h}$ post-fertilisation, $25 \mathrm{~h}$ post-fertilisation, hybridised with the Eggs 24 antisense cRNA probe. (B) Carp embryos (bottom to top), $12 \mathrm{~h}$ post-hatching, $30 \mathrm{~h}$ post-fertilisation, $25 \mathrm{~h}$ postfertilisation, hybridised with the Eggs22 antisense cRNA probe. (C,D) View of trunk musculature from larvae $12 \mathrm{~h}$ post-hatching hybridised with Eggs22 sense cRNA (C) and antisense cRNA (D). (E,F) Underside view of the head of carp larvae (12h post-hatching) hybridised with Eggs24 antisense cRNA (E) and Eggs22 antisense cRNA (F). The arrowhead highlights expression of Eggs22 in the developing lower jaw. (G) Eosin-stained transverse section $(10 \mu \mathrm{m})$ through the trunk of a $25 \mathrm{~h}$ post-fertilisation embryo which had previously been hybridised (wholemount) with antisense cRNA for the Eggs24 gene (dorsal is to the left of the micrograph). Eosin staining is pink, hybridised probe is purple. (H) Longitudinal eosinstained section through the trunk of a $12 \mathrm{~h}$ post-hatching larva which had previously been hybridised with antisense Eggs 22 cRNA. Note the muscle fibres running from myosept to myosept and the stronger hybridisation (purple) at the myoseptal ends of the fibres (arrowheads). Scale bars: A,B, $1 \mathrm{~mm}$; C-F, $250 \mu \mathrm{m} ; \mathrm{G}, \mathrm{H}, 50 \mu \mathrm{m}$.
Eggs24 MyoHC transcripts coincided with the switch from the exclusive expression of $\beta$-actin to expression of both $\beta$ - and $\alpha$ actin (sarcomeric actin) and occurred just before the first movements of the embryo were observed. Expression of both $\mathrm{MyoHC}$ transcripts followed the normal progression of muscle development (Akster and Koumans, 1995), being initially expressed in the rostral region and progressing caudally. Such an expression pattern is also observed with the Xenopus laevis E3 MyoHC gene. The Xenopus laevis E19 MyoHC gene, however, is unusual in that it is expressed counter to this, starting caudally and progressing rostrally (Radice, 1995). Unlike the Xenopus laevis E3 and E19 MyoHC genes, no predominance in fibre type expression was observed for the carp Eggs 22 and Eggs 24 transcripts. Both carp transcripts were co-expressed at equivalent levels in developing white muscle fibres but not in the peripheral layer of developing red muscle fibres. Only the muscles of the lower jaw showed a differential expression pattern in that these muscles expressed the Eggs 22 MyoHC transcript but not the Eggs24 transcript. Why these muscles should differ in this respect is unknown.

A distinctive chevron pattern of expression was observed in the trunk musculature with both transcripts, and this is likely to be a consequence of the mechanism of longitudinal muscle fibre growth. In mammalian muscle, it has been shown that muscle fibres increase in length by the addition of new sarcomeres onto the ends of existing myofibrils (Griffin et al., 1971; Williams and Goldspink, 1971), and it is likely that the same mechanism of growth is adopted by other species, including fish. The appearance of the distinctive chevron pattern of staining can be explained by an accumulation of message at the myoseptal ends of the fibres, which are the sites of new protein synthesis for incorporation into the sarcomeres. Indeed, longitudinal wax-embedded sections (Fig. 5H) directly show this accumulation of message adjacent to the myosepta. This also suggests that transport of $\mathrm{MyoHC}$ mRNA to the site of new sarcomere production is occurring. Localisation of mRNA has previously been described for vimentin, actin and tubulin, which associate closely with the cytoplasmic actin filaments (Singer et al., 1989), and for myosin heavy chain, which accumulates at the myotendinous junction in stretchhypertrophied rabbit skeletal muscle (Dix and Eisenberg, 1990). The 3'UTR has been implicated in the transport of mRNA to different cellular locations (Wiseman et al., 1997a,b) and, with this possibility in mind, the 3'UTR sequences of the two carp $M y o H C$ transcripts isolated in the present study were aligned with corresponding sequences from all the $\mathrm{MyoHC}$ genes currently in the EMBL database. From this analysis, a conserved sequence motif of 10 base pairs (AAAATGTGAA) was found to be present in the $3^{\prime}$ UTRs of $M y o H C$ isoforms from a diverse range of species, including the carp Eggs24 transcript (Table 1). Because this motif has been conserved over such a diverse range of species, whilst the flanking sequence as a whole shows no conservation across species, a biological function for this region seems very likely. It is possible that this sequence 
Table 1. Conserved sequence motif in the 3'untranslated regions of myosin heavy chain isoforms from a diverse range of species

\begin{tabular}{|c|c|c|c|}
\hline Isoform & Position & Sequer & \\
\hline Carp Eggs 24 & $45-54$ & $\begin{array}{l}\text { tttgtatctg } \\
\text { attgttcaat }\end{array}$ & AAAATGTGAA \\
\hline Chicken fast & $40-49$ & $\begin{array}{l}\text { aggcatgcat } \\
\text { cctctgtgtt }\end{array}$ & AAAATGTGAA \\
\hline Chicken embryonic 1 & $40-49$ & $\begin{array}{l}\text { agaattgcac } \\
\text { attctatcac }\end{array}$ & AAAATGTGAA \\
\hline Chicken embryonic 2 & $40-49$ & $\begin{array}{l}\text { agaattgcac } \\
\text { attctatcac }\end{array}$ & AAAATGTGAA \\
\hline Human IIX & $41-50$ & $\begin{array}{l}\text { agaaatgcac } \\
\text { aatctttgtc }\end{array}$ & AAAATGTGAA \\
\hline Pig IIa & $42-51$ & $\begin{array}{l}\text { agagaggcac } \\
\text { gtctttgcgt }\end{array}$ & AAAATGTGAA \\
\hline Rabbit IIb & $40-49$ & $\begin{array}{l}\text { agaaatgcac } \\
\text { gttcaaagtc }\end{array}$ & AAAATGTGAA \\
\hline Rabbit IIX & $40-49$ & $\begin{array}{l}\text { agaaatgcac } \\
\text { actctttgtc }\end{array}$ & AAAATGTGAA \\
\hline Rat IIa & $42-51$ & $\begin{array}{l}\text { agaaaggcac } \\
\text { gcctttggtc }\end{array}$ & AAAATGTGAA \\
\hline Rat IIX & $40-49$ & $\begin{array}{l}\text { agagatgagc } \\
\text { gatctttgtc }\end{array}$ & AAAATGTGAA \\
\hline Xenopus E19 & $38-47$ & $\begin{array}{l}\text { tgaaatttgc } \\
\text { tttctcttcc }\end{array}$ & AAAATGTGAA \\
\hline Xenopus E15 & $38-47$ & $\begin{array}{l}\text { tgaaatttgc } \\
\text { tttcttccct }\end{array}$ & AAAATGTGAA \\
\hline
\end{tabular}

The sequence motif is given in bold uppercase.

Position indicates the number of nucleotides after the stop codon at which the sequence motif appears.

The source of the sequence data (EMBL accession numbers) is as follows: carp Eggs24, AJ009734; chicken fast, M16557; chicken embryonic 1, J00892; chicken embryonic 2, M12086; human IIX, X03740; pig IIa, S. Ennion unpublished results; rabbit IIb, Y1320; rabbit IIX, Y13202; rat IIa, X72589; rat IIX, X72591; Xenopus E19, M27235; Xenopus E15, M27237.

motif could be a localization signal involved in the transport of MyoHC mRNA. However, there are equally as many MyoHC 3'UTR sequences that do not contain this motif, including the Eggs22 transcript characterised in the present study, and further studies are required to investigate this.

Expression of the Eggs22 and Eggs24 MyoHC transcripts is undetectable 2 weeks post-hatching when these transcripts are replaced by mRNAs for adult/juvenile isoform types. Both transcripts in this study are expressed in the very early stages of muscle formation, and one possible explanation for the need for separate developmental and adult-type isoforms is that these embryonic isoform types are necessary for the initial myofibril structure to be laid down. This structure can subsequently be replaced by the adult isoforms by the law of mass action (Goldfine et al., 1991). Also, the need for separate developmental isoforms could be at the cross-bridge function level, with the developmental isoforms conferring more optimal actin binding or ATPase properties. Indeed the tailbeat frequency required for efficient locomotion changes dramatically throughout development in fish, and it is likely that different MyoHC isoforms would be required.

The muscle myosin/actin system is a very old molecular motor mechanism (for a review, see Warrick and Spudich, 1987) which is thought to have evolved first in primitive metazoan animals as a means of pumping haemolymph in circulatory systems. Even prior to this, the myosin/actin motors no doubt evolved in single-celled organisms in nonmuscle cytoskeletal systems involved in ameboid movements (Hammer et al., 1987). The MyoHC gene family in presentday vertebrates includes individual genes that encode different isoforms which are developmentally regulated and which have different contractile characteristics. Skeletal muscle differs from cardiac muscle in that there are distinct embryonic and neonatal $\mathrm{MyoHC}$ genes expressed in this tissue that are not expressed in the heart. The heart develops very early and shows a gradual increase in size. However, skeletal muscle shows a rapid increase in mass just before or just after birth/hatching. Although it was known that embryonic $\mathrm{MyoHC}$ genes are expressed in developing mammalian muscle, it is interesting, from the point of view of developmental mechanisms, that the same initial steps in forming the myofibril infrastructure in lower vertebrates, such as fish, also involve the expression of a specific embryonic MyoHC gene or genes. In the carp, the Eggs22 and Eggs24 transcripts show more sequence homology with other carp $M y o H C$ genes than with mammalian embryonic genes and it seems, therefore, that the system of sequential gene expression may have evolved more than once, indicating that the embryonic MyoHCs play an important role in early skeletal muscle development.

We wish to thank Claire Underwood and David Sutton for technical assistance and Dr Chris Thrasivoulou for advice on microscopy. This work was funded by a grants from NERC and the EU. The British Council originally provided an exchange travel grant. S.E was funded by a Dowager Countess Eleanor Peel Research Fellowship.

\section{References}

Akster, H. A. (1983). A comparative study of fibre type characteristics and terminal innervation in head and axial muscle of the carp (Cyprinus carpio L.): a histochemical and electronmicroscopial study. Neth J. Zool. 33, 164-188.

Akster, H. A. and Koumans, J. T. M. (1995). Myogenic cells in development and growth of fish. Comp. Biochem. Physiol. 110A, 3-20.

Alami-Durante, H., Fauconneau, B., Rouel, M., Escaffre, A. M. and Bergot, P. (1997). Growth and multiplication of white skeletal muscle fibres in carp larvae in relation to somatic growth rate. $J$. Fish Biol. 50, 1285-1302.

Barbet, J. P., Thornell, L. E. and Butler-Browne, G. S. (1991). Immunocytochemical characterisation of two generations of fibers 


\section{Developmental myosin heavy chain isoforms in carp 1089}

during the development of the human quadriceps muscle. Mech. Dev. 35, 3-11.

Chomczynski, P. and Sacchi, N. (1987). Single-step method of RNA isolation by acid guanidinium thiocyanatephenolchloroform extraction. Analyt. Biochem. 162, 156-159.

Church, G. M. and Gilbert, W. (1984). Genomic sequencing. Proc. Natl. Acad. Sci. USA 81, 1991-1995.

Devoto, S. H., Melancon, E., Eisen, J. S. and Westerfield, M. (1996). Identification of separate slow and fast muscle precursor cells in-vivo, prior to somite formation. Development $\mathbf{1 2 2}$, 3371-3380.

Dix, D. J. and Eisenberg, B. R. (1990). Myosin mRNA accumulation and myofibrillogenesis at the myotendinous junction of stretched muscle fibers. J. Cell Biol. 111, 1885-1894.

Eller, M., Stedman, H. H., Sylvester, J. E., Fertels, S. H., Rubinstein, N. A., Kelly, A. M. and Sarkar, S. (1989a). Nucleotide sequence of full length human embryonic myosin heavy chain cDNA. Nucleic Acids Res. 17, 3591-3592.

Eller, M., Stedman, H. H., Sylvester, J. E., Fertels, S. H., Wu, Q. L., Raychowdhury, M. K., Rubinstein, N. A., Kelly, A. M. and Sarkar, S. (1989b). Human embryonic myosin heavy chain cDNA. Interspecies sequence conservation of the myosin rod, chromosomal locus and isoform specific transcription of the gene. FEBS Lett. 256, 21-28.

Ennion, S., Gauvry, L., Butterworth, P. and Goldspink, G. (1995a). Small-diameter white myotomal muscle fibres associated with growth hyperplasia in the carp (Cyprinus carpio) express a distinct myosin heavy chain gene. J. Exp. Biol. 198, 1603-1611.

Ennion, S., Sant'ana Pereira, J., Sargeant, A. J., Young, A. and Goldspink, G. (1995b). Characterization of human skeletal muscle fibres according to the myosin heavy chains they express. J. Muscle Res. Cell Motil. 16, 35-43.

Feghali, R. and Leinwand, L. A. (1989). Molecular genetic characterization of a developmentally regulated human perinatal myosin heavy chain. J. Cell Biol. 108, 1791-1797.

Feinberg, A. P. and Vogelstein, B. (1984). Addendum: A technique for radiolabelling DNA restriction endonuclease fragments to high specific activity. Analyt. Biochem. 137, 266-267.

Gauvry, L. and Fauconneau, B. (1996). Cloning of a trout skeletal myosin heavy chain expressed both in embryo and adult muscles and in myotubes neoformed in vitro. Comp. Biochem. Physiol. 115B, 183-190.

Gerlach, G. F., Turay, L., Malik, K. T., Lida, J., Scutt, A. and Goldspink, G. (1990). Mechanisms of temperature acclimation in the carp: a molecular biology approach. Am. J. Physiol. 259, R237-R244.

Goldfine, S. M., Einheber, S. and Fischman, D. A. (1991). Cell free incorporation of newly synthesized myosin subunits into thick filaments. J. Muscle Res. Cell Motil. 12, 161-170.

Griffin, G., Williams, P. and Goldspink, G. (1971). Region of longitudinal growth in striated muscle fibres. Nature New Biol. 232, $28-29$.

Hammer III, J. A., Bowers, B., Paterson, B. M. and Korn, E. D. (1987). Complete nucleotide sequence and deduced polypeptide sequence of a non-muscle myosin heavy chain from Acanthamoeba; evidence of a hinge in the rod-like tail. J.Cell Biol. 105, 913-925.

Harvey, R. J. and Darlison, M. G. (1991). Random-primed cDNA synthesis facilitates the isolation of multiple $5^{\prime}$-cDNA ends by RACE. Nucleic Acids Res. 19, 4002.

Higgins, D. G. and Sharp, P. M. (1988). Clustal: A package for performing multiple sequence alignment on a microcomputer. Gene 73, 237-244.

Hixson, J. E. and Britten, M. L. (1988). The baboon beta-myosin heavy-chain gene: construction and characterization of cDNA clones and gene expression in cardiac tissues. Gene 64, 33-42.

Hofmann, S., Dusterhoft, S. and Pette, D. (1988). Six myosin heavy chain isoforms are expressed during chick breast muscle development. FEBS Lett. 238, 245-248.

Hughes, S. M., Cho, M., Karsch-Mizrachi, I., Travis, M., Silberstein, L. and Blau, H. M. (1993). Three slow myosin heavy chains sequentially expressed in developing mammalian skeletal muscle. Dev. Biol. 158, 183-199.

Jaenicke, T., Diederich, K. W., Haas, W., Schleich, J., Lichter, P., Pfordt, M. and Vosberg, H. P. (1990). The complete sequence of the human beta-myosin heavy chain gene and a comparative analysis of its product. Genomics 8, 194-206.

Karsch-Mizrachi, I., Travis, M., Blau, H. and Leinwand, L. A. (1989). Expression and DNA sequence analysis of a human embryonic skeletal muscle myosin heavy chain gene. Nucleic Acids Res. 17, 6167-6179.

Kavinsky, C. J., Umeda, P. K., Levin, J. E., Sinha, A. M., Nigro, J. M. and Jakovcic, S. (1984). Analysis of cloned mRNA sequences encoding subfragment 2 and part of subfragment 1 of alpha- and beta-myosin heavy chains of rabbit heart. J. Biol. Chem. 259, 2775-2781.

Kraft, R., Bravo-Zehnder, M., Taylor, D. A. and Leinwand, L. A. (1989). Complete nucleotide sequence of full length cDNA for rat beta cardiac myosin heavy chain. Nucleic Acids Res. 17, 7529-7530.

Marchuk, D., Drumm, M., Saulino, A. and Collins, F. S. (1991). Construction of T-vectors, a rapid and general system for direct cloning of unmodified PCR products. Nucleic Acids Res. 19, 1154.

Matsuoka, R., Beisel, K. W., Furutani, M., Arai, S. and Takao, A. (1991). Complete sequence of human cardiac alpha-myosin heavy chain gene and amino acid comparison to other myosins based on structural and functional differences. Am. J. Med. Genet. 41, 537-547.

McKoy, G., Léger, M., Bacou, F. and Goldspink, G. (1998). Differential expression of myosin heavy chain mRNA and protein isoforms in four functionally diverse rabbit skeletal muscles during pre- and postnatal development. Dev. Dyn. 211, 193-203.

McNally, E. M., Gianola, K. M. and Leinwand, L. A. (1989). Complete nucleotide sequence of full length cDNA for rat alpha cardiac myosin heavy chain. Nucleic Acids Res. 17, 7527-7528.

Molina, M. I., Kropp, K. E., Gulick, J. and Robbins, J. (1987). The sequence of an embryonic myosin heavy chain gene and isolation of its corresponding cDNA. J. Biol. Chem. 262, 6478-6488.

Narusawa, M., Fitzsimons, R. B., Izumo, S., Nadal-Ginard, B. and Rubinstein, N. A. (1987). Slow myosin in developing rat skeletal muscle. J. Cell Biol. 104, 447-459.

Periasamy, M., Wieczorek, D. F. and Nadal-Ginard, B. (1984). Characterization of a developmentally regulated perinatal myosin heavy-chain gene expressed in skeletal muscle. J. Biol. Chem. 259, 13573-13578.

Radice, G. P. (1995). Spatial expression of two tadpole stage specific myosin heavy chains in Xenopus laevis. Acta Anat. 153, 254-262.

Radice, G. P. and Malacinski, G. M. (1989). Expression of myosin heavy chain transcripts during Xenopus laevis development. Dev. Biol. 133, 562-568.

Rowlerson, A., Scapolo, P. A., Mascarello, F., Carpene, E. and 
Veggetti, A. (1985). Comparative study of myosins present in the lateral muscle of some fish: species variations in myosin isoforms and their distribution in red, pink and white muscle. J. Muscle Res. Cell Motil. 6, 601-640.

Saez, L. and Leinwand, L. A. (1986). Characterization of diverse forms of myosin heavy chain expressed in adult human skeletal muscle. Nucleic Acids Res. 14, 2951-2969.

Sanger, F., Nicklen, S. and Coulson, A. R. (1977). DNA sequencing with chain-terminating inhibitors. Proc. Natl. Acad. Sci. USA 74, 5463-5467.

Singer, R. H., Langevin, G. L. and Lawrence, J. B. (1989). Ultrastructural visualization of cytoskeletal mRNAs and their associated proteins using double-label in situ hybridization. J. Cell Biol. 108, 2343-2353.

Stedman, H. H., Kelly, A. M. and Rubinstein, N. A. (1990). Isoform-specific cDNAs for human embryonic, neonatal and slow skeletal myosin heavy chains. Ann. N.Y. Acad. Sci. 599, 119-126.

Strehler, E. E., Strehler-Page, M. A., Perriard, J. C., Periasamy,
M. and Nadal-Ginard, B. (1986). Complete nucleotide and encoded amino acid sequence of a mammalian myosin heavy chain gene. Evidence against intron-dependent evolution of the rod. $J$. Mol. Biol. 190, 291-317.

Warrick, H. M. and Spudich, J. A. (1987). Myosin structure and function in cell motility. Annu. Rev. Cell. Biol. 3, 379-421.

Weydert, A., Barton, P., Harris, A. J., Pinset, C. and Buckingham, M. (1987). Developmental pattern of mouse skeletal myosin heavy chain gene transcripts in vivo and in vitro. Cell 49, 121-129.

Williams, P. E. and Goldspink, G. (1972). Longitudinal growth of striated muscle fibres. J. Cell Sci. 9, 751-767.

Wiseman, J. W., Glover, L. A. and Hesketh, J. E. (1997a). Evidence for a localization signal in the $3^{\prime}$ untranslated region of myosin heavy chain messenger RNA. Cell Biol. Int. 21, 243-248.

Wiseman, J. W., Glover, L. A. and Hesketh, J. E. (1997b). Evidence for a localisation signal in the $3^{\prime}$-untranslated region from vimentin messenger RNA. Int. J. Biochem. Cell Biol. 29, 1013-1020. 